\title{
Los procesos políticos en fases de cambio de régimen
}

Gonzalo Varela Petito UAM-XOCHIMILCO

Se contrastan cuatro casos, señalando la diferencia conceptual entre transición a la democracia, cambio de régimen y primer gobierno de transición. Se define el comportamiento de los partidos como bisagra política de la transición. Se mencionan

otros actores: el sindicalismo y la Iglesia católica y, especialmente, las fuerzas armadas, que cumplen también una función de bisagra política. Las diferentes variables permiten valorar las circunstancias y la dinámica política hacia el fin del milenio.

\section{INTRODUCCIÓN}

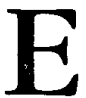

n este artículo comparativo recurriremos al contraste de distintas variables pertinentes para el análisis de la situación del primer gobierno de transición a la democracia en cuatro países latinoamericanos: Argentina, Brasil, México y Uruguay.

Se contemplará especialmente a los partidos como bisagras políticas de la transición, tanto en su dinámica interna como en la relación con el régimen autoritario y el nuevo sistema político y las sociedades civiles reanimadas al amparo de la transición. Incluiremos así mismo a otros actores, sobre todo $y$ por razones obvias, a las fuerzas armadas, que en estas circunstancias son también una fuerza de bisagra, porque de forma más o menos decisiva intervienen en las negociaciones de la transición -aun en situaciones para ellas catastróficas como la de Argentina luego de la guerra de las Malvinasy porque siguen existiendo con una perspectiva de largo plazo, aunque ciertamente con distinto papel político, en la nueva coyuntura democrática. También a la Iglesia católica, que es, en la mayoría de los países latinoamericanos, sumamente influyente, con 
sesgos conservadores o progresistas, pero en todo caso volcada últimamente en forma expresa a un compromiso con el régimen democrático. Y claro está, el sindicalismo, fuerza clave integrada a lo que llamamos sociedad civil, pero que merece una consideración especial por su tradición histórica, su incidencia en la economía y sus relaciones con los partidos políticos y con los gobiernos.

No trataremos todas estas cuestiones por igual en todos los países, dado que su incidencia es cambiante en cada caso. Pero siguiendo este esquema haremos un repaso caso por caso, proponiendo al final algunas observaciones de carácter general.

Es necesario aclarar que hacemos una diferencia conceptual entre transición a la democracia, cambio de régimen y primer gobierno de transición a la democracia. La transición a la democracia se inicia por lo general antes de la terminación del régimen autoritario propiamente dicho por medio de acciones que son sobre todo de protesta y negociación, acompañadas a veces por reformas que suavizan algunos aspectos del régimen. El cambio de régimen se produce cuando, si no todos, al menos los rasgos esenciales del autoritaritarismo desaparecen para ser sustituidos por otros definitorios de la democracia, como el pluralismo político e ideológico con nulas o pocas restricciones, el respeto a los derechos humanos, cierta separación de poderes y la realización de elecciones libres. El primer gobierno que se desempeña en estas condiciones luego de un periodo de autoritarismo es -obviamente- lo que denomina- mos primer gobierno de transición democrática. ${ }^{1}$

\section{ARGENTINA}

En Argentina, como en otros países, se verificó durante el primer gobierno de la transición a la democracia un hecho también notorio en otros continentes y épocas (por ejemplo, en Europa occidental luego de la segunda guerra mundial) que es el de la recuperación del papel de los partidos y, junto con ellos, de los políticos profesionales. No quiere decirse con esto que todo siga como estaba antes. Por el contrario, las continuidades se dan en panoramas en que ha habido profundos cambios: en las economías, en las relaciones internacionales y también en las culturas políticas de cada país. El resurgir de los políticos y de la política de partidos tiene que ver con la reafirmación de algunos viejos rasgos pero en un contexto de transformaciones.

No se trata de una restauración en sentido literal. En Argentina, no sólo los partidos han pasado a tener un papel más decisivo del que tenían antes, sino que -así como en México el Partido Revolucionario Institucional (PRI) se ha visto forzado a una lenta pero progresiva liberación de la tutela presidencial- su partido actualmente más

1 Cabría discutir si no puede también calificarse como tal a la democracia en el contexto de una situación todavía autoritaria (por ejemplo, el gobierno de Adolfo Suárez en España durante su primer tramo), pero preferimos reservar esta denominación para una administración que se desempeña ya en una situación democrática. 
fuerte, el justicialismo, que se conformara como una organización carismática bajo el arbitrio de Juan Domingo Perón, no sólo supo sobrevivir a la desaparición física de éste sino convertirse en un partido moderno, con características renovadas. Ello se da en una circunstancia en que actores anteriormente más fuertes que los partidos - los militares, la Iglesia e inclusive los mismos sindicatos- han perdido peso, lo que es indicador de la liquidación del sistema político formado a raíz de la Revolución Libertadora de 1955, en que las fuerzas armadas eran el fiel de la balanza y los civiles apostaban y a menudo inclusive invocaban la intervención castrense. ${ }^{2}$

El cambio no inhibe a la figura presidencial, pero el Congreso tiene también un papel relevante. Esto se verificó sobre todo durante la presidencia de Raúl Alfonsín (1983-1989) que constituyó un gobierno débil por varias razones: probablemente, en primer lugar, por la falta de experiencia del Partido Radical y del mismo presidente Alfonsín en el manejo de la administración pública; en segundo lugar por la permanencia de un factor militar que, si bien en decadencia, siguió planteando desafios desestabilizadores; en tercer lugar por el titubeo en el manejo económico, debido tanto al experimentalismo de sucesivos ministerios como al choque entre las creencias económicas del presidente y una realidad económica y financiera internacional también profundamente cambiada, y que imponía a las políticas nacionales

${ }^{2}$ Véase Rouquié, Pouvoir, 1978. constricciones a las que difícilmente podían escapar.

Más allá de lo puramente económico en los años ochenta presenciamos en América Latina la existencia de otros gobernantes como Hernán Siles Suazo en Bolivia, Alán García en Perú o Belisario Betancourt en Colombia, que fueron presas de la contradicción entre sus creencias ideológicas y la realidad que les tocó vivir. En el caso de Alfonsín, tres fueron los problemas principales que enfrentó: incapacidad de manejar la nueva situación económica; persistencia con relativa fuerza de actores conservadores heredados del sistema político que surgió de la Revolución Libertadora, y también, pese a una indudable evolución del sistema de partidos, el papel obstruccionista que por razones de conveniencia y cálculo jugó a menudo el partido peronista desde el Congreso.

El quid del cambio político en la etapa inmediatamente posterior a la restauración de la democracia se asentaba en la reestructuración de las relaciones entre los actores y de cada uno de éstos con el sistema político. Mirado el largo plazo puede decirse que las tres fuerzas que encumbraron a Perón en 1945 -los militares, los sindicatos y la Iglesia católica- siguieron siendo decisivas hasta los años ochenta. Con posterioridad a 1955 los militares y la Iglesia sostuvieron posiciones conservadoras. Pero el sindicalismo justicialista no careció de ambigüedades pues, como han señalado diversos analistas, en las nuevas "décadas infames" de 1955 a 1973 existieron acuerdos tácitos o implícitos entre las dirigencias sindicales y la cúpula militar. 
Cuando el gobierno de Alfonsín se inauguró en 1983 debió tratar con estos tres actores y por distintas razones los tendría en la oposición. Éstos y otros elementos de tipo económico y político-institucional iban finalmente a determinar, en 1989, un panorama de descomposición del nuevo gobierno.

Los militares estaban acabados como factor político dominante por lo menos desde 1983. Los graves costos humanos de la dictadura de 1976 1983, la dificultad de seguir en lo económico la relativamente exitosa ruta de los regímenes militares brasileño o inclusive chileno, y el desastroso colofón de la guerra de las Malvinas (que había producido una deshonrosa derrota también en lo militar), habían llevado a un punto muerto a la institución castrense. Pero a ésta todavía le quedaban reivindicaciones gremiales que defender, como la exigencia de impunidad por las violaciones a los derechos humanos producidas durante la dictadura. El gobierno de Alfon. sín debió así enfrentar más de una sublevación de cuarteles. Paralelamente se dio también la fundación de partidos por iniciativa de militares retirados (algunos como Aldo Rico involucrados en alguno de los mencionados levantamientos). Pero si bien éstos pudieron aparecer en algún momento como una nueva y amenazadora forma de reavivar a un sector acostumbrado a décadas de influyente participación política, sirvieron finalmente para una inclusión controlada en el régimen democrático de remanentes del activismo militar (y sus admiradores civiles) no resignados a perder totalmente su presencia en el panorama nacional.
Los sindicatos, al igual que la rama partidaria del peronismo, chocaron con Alfonsín por razones fáciles de entender. El radicalismo, al superar en forma aplastante al justicialismo en los comicios de 1983, había cuestionado su aparente invencibilidad electoral y ello afectaba también a las organizaciones laborales ligadas al peronismo. Sin embargo, la oposición sindical no sólo tenía que ver con el aspecto político-electoral propiamente dicho, sino también con la defensa de una posición corporativa ganada por medio del control de la fuerza de trabajo en las empresas, que no había sido básicamente tocada durante el exilio de Perón de 1955 a 1973 ǹi tampoco del todo desmantelada por la dictadura militar. Pero algo más fuerte que los militares actuaba ahora contra ella, y era la situación de la economía argentina y la inminencia cada vez más irresistible de la reforma estructural que, al propiciar la apertura del mercado interno y por tanto cambios muy importantes en la cantidad, calidad y organización de la fuerza de trabajo, determinaría también el cambio del peso político específico de las agremiaciones laborales.

No sería sin embargo el gobierno radical el que consagrara estas reformas, pues el alfonsinismo terminó haciendo importantes concesiones a la dirigencia sindical peronista. En este y otros aspectos los radicales cayeron en la indefinición, la indecisión y finalmente en la disgregación. Sería paradójicamente (pero no tan inexplicablemente, dado su ascendiente sobre el sindicalismo) un gobierno justicialista -el de Carlos Saúl Menem iniciado en 


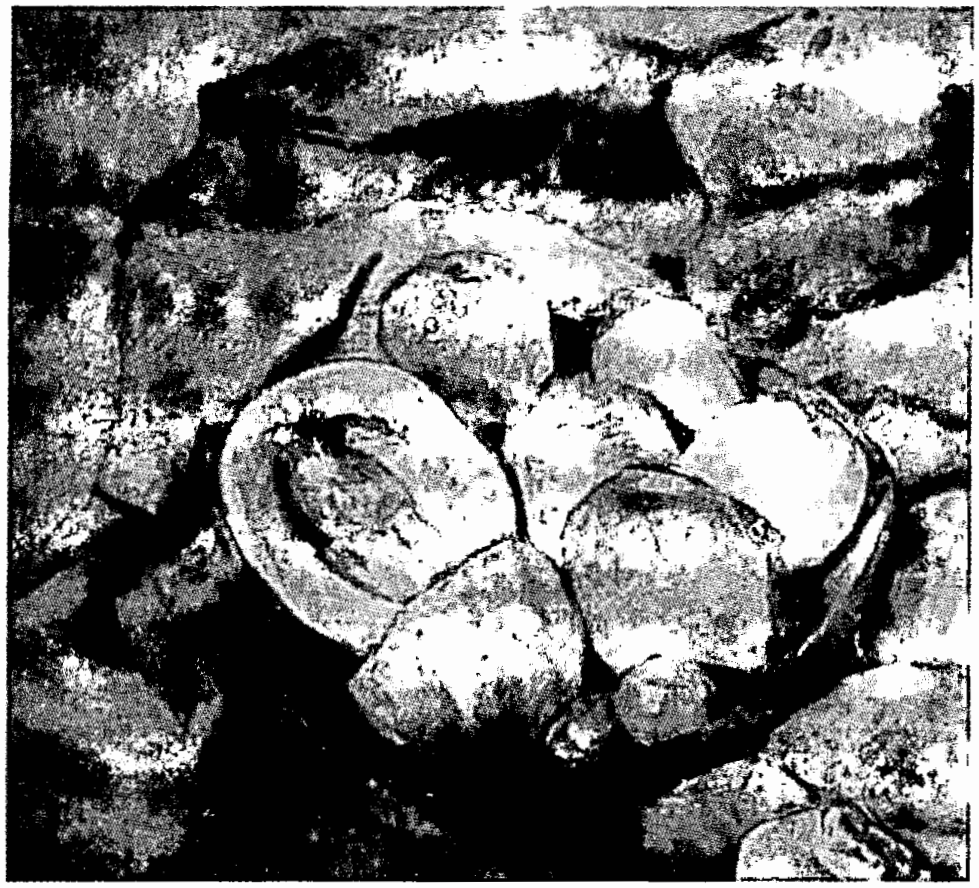

1989- el que formalizaría los cambios en esta materia.

Por su parte la Iglesia católica argentina no sólo había seguido por el camino del conservadurismo mientras otras en el subcontinente se "aggiornaban", sino que otorgó una complicidad con ribetes escandalosos a la dictadura de 1976 a 1983. A diferencia de cleros como los de Brasil, Centroamérica y en menor medida México (y España en Europa) que, a pesar de tener antecedentes ultramontanos y de complicidad con el poder ante la vivencia de las sistemáticas violaciones a los derechos humanos y políticos, acabaron generando una actitud de resistencia al autoritarismo (a menudo sin abandonar una postura conservadora en otros aspectos morales y políticos), ${ }^{3}$ en Argentina los sacerdotes no sólo toleraron sino que encubrieron y secundaron la terrible represión militar. Aparte de esta culpa, chocaron también con Alfonsín a causa del proyecto

${ }^{3}$ Lo que nos hace ver que las cuestionables posturas políticas de la mayoría de la Iglesia católica argentina no se pueden atribuir solamente a su formación conservadora. 
finalmente aprobado de ley del divorcio, una iniciativa que en más de un país latinoamericano había sido consagrada desde principios de siglo, pero que en un país tan modernizado como Argentina, quizá debido al peso que en el mismo ha mantenido la Iglesia católica, no había logrado establecerse antes de la década de los ochenta.

En cuanto al partido justicialista, como ya dijimos, fue la principal fuerza de oposición en el Congreso. Pero si bien sus acciones de obstrucción -por ejemplo, hacia la política económica de Alfonsín y sus ministros- tenían un sesgo oportunista (bien pronto un gobierno peronista aplicaría medidas mucho más crudas), en conjunto la práctica del justicialismo como la de la mayoría de las fuerzas civiles se inclinaría hacia la consolidación democrática, descartando el flirteo con los militares y la ilegalidad que había sido una de las causas de la larga inestabilidad constitucional argentina a partir de 1930.

Una visión de conjunto de este gobierno de restauración de la democracia en Argentina nos hace dudar de que sus penurias se derivaran de las limitaciones del presidencialismo - según sugiere una polémica reciente-, sino de instituciones políticas secularmente débiles (tanto las democráticas como las autoritarias), falta de deci-

${ }^{4}$ Véase Linz y Valenzuela, Failure, 1994, vol. 2. No negamos la argumentación de los compiladores, pero dados los pocos casos nacionales que presentan y la disparidad de las conclusiones de cada uno, no parece que se pueda llegar a una posición clara sobre el tema de las presumibles ventajas del parlamentarismo sobre el presidencialismo. sión y de definición en el rumbo de las políticas y un liderazgo atrapado en las contradicciones surgidas del choque de sus compromisos morales e ideológicos con los desafíos que la realidad cotidiana le iba planteando. No obstante, el rumbo hacia la consolidación de la democracia no se torció, posiblemente porque las mismas circunstancias nacionales e internacionales lo favorecieron, pero también porque los principales actores de este proceso, en forma decidida o a regañadientes, eligieron dicho camino.

\section{BRASIL}

En Brasil si bien el panorama es -como en los demás países aquí examinadosdistinto y específico, podemos también referir el análisis al mismo esquema: cambios en el régimen y en la cultura políticos en relación con transformaciones en el sistema político determinadas por el peso específico de los actores y de sus relaciones recíprocas. El grupo de actores es el mismo: partidos y políticos profesionales (dos grupos que en Brasil aparecen más separados que en otros países de la región), militares, eclesiásticos y organizaciones corporativas sindicales.

Es de destacar que en Brasil el retorno a la democracia se da por un sendero trazado por el régimen militar y de acuerdo con sus reglas. A diferencia de Uruguay o Chile no hubo un plebiscito que forzara el camino hacia la democracia, ni una derrota como en Argentina, que restringiera el margen de maniobra de los militares para negociar o imponer condiciones a sus 
sucesores civiles. Y si bien, como fue la regla en todos los casos, incluso a la postre en Argentina, se aseguró la intangibilidad de los cuerpos castrenses de cara a las denuncias por violación de derechos humanos, éstas pesaban menos en Brasil que en otros países. También es de tenerse en cuenta que, por haber hecho uso del personal civil político tradicional para ayudarse en la administración de un país tan extenso y complejo como es Brasil, la dictadura castrense en parte podía también diluir más facilmente responsabilidades facilitando el traslado del poder a los políticos.

Como ya adelantamos, en Brasil la diferencia entre elite política y partidos se vuelve especialmente relevante. Mucho se ha hablado de la volatilidad de este sistema de partidos, que no tiene la fijeza ni la implantación social que ostentan las organizaciones de otras naciones de la región. En perspectiva histórica podemos suponer que ello se debe al hecho de que en Brasil el Estado ha pesado más que los partidos.

Con la relativa excepción de Chile, desde la independencia hasta nuestro siglo el conjunto de los países latinoamericanos tuvo Estados débiles, cuando no inexistentes, ${ }^{5}$ pero a cambio de ello culturas de partidos (o de facciones) muy intensas. En algunos países como Uruguay se ha hablado de una sustitución de facto del Estado por los partidos en la tarea de socialización política de la población; en Chile puede decirse que hubo, durante el siglo

\footnotetext{
'Algunos autores como Alain Touraine han insistido en ello; véase Actores, 1987.
}

XIX, un equilibrio entre ambos elementos; el caso brasileño, en cambio, parece ilustrar el extremo contrario: una virtual anulación del papel de socialización de los partidos en beneficio del Estado. Allí la tradición ha sido que los partidos tengan un papel sobre todo electoral, con baja incidencia en la difusión del sentimiento patriótico, la inserción social de los pobres o los inmigrantes, la educación cívica e incluso otros elementos bien conocidos, como la distribución de bienes a seguidores por medio de mecanismos de clientela. Esto permite que la elite de los políticos profesionales se haya convertido en un estamento flotante que se desplaza con relativa facilidad de un partido a otro. Con esto los partidos, si bien no desaparecen, quedan disminuidos en su papel. Al no haber socialización ni cultura política fuertemente asociada a ellos, la constancia de la afiliación política de elites o masas nunca ha sido vista como una cuestión de vida o muerte, como ha sucedido en otros países latinoamericanos (sobre todo en el pasado). Mucho se ha hablado del oportunismo o el cínico manejo del clientelismo por los políticos profesionales en muchos de estos países, pero el hecho es que este pragmatismo frecuentemente se combinaba con un real apego a una cultura partidaria asentada en factores ideológicos y afectivos que trascendían el mero intercambio de beneficios.

En muchos de estos países los partidos predominantes fueron cambiando con el tiempo, reconstruyéndose los sistemas partidarios y los esquemas de lealtades derivados de ellos, pero 
esto no sucedía de un día para otro y por lo demás las lealtades reconstruidas no eran menos sólidas que las antecedentes. Sólo en en Brasil, y tal vez también en Ecuador, los políticos podían independizarse de los partidos y organizarlos según su conveniencia, debido al escaso peso que éstos tenían en el sistema político y al escaso fervor que levantaban entre sus votantes.

Ante tal hecho debemos tratar de identificar cuáles son los factores y actores que sustituyen el papel de los partidos, pues no podemos pensar que éste sea llenado enteramente por el Estado. La burocracia o (si se trata de un Estado modernizado) la tecnocracia estatal, cuandó actúa como un actor coherente con posiciones unificadas pueden jugar un importante papel, pero necesita otros socios para hacer funcionar el sistema político. En los países latinoamericanos que han vivido experiencias populistas (Brasil, México y Argentina) y donde, con matices, el papel de los partidos no ha sido tan importante en el pasado inmediato, este socio suele encontrarse en las dirigencias corporativas sindicales. Dadas las modalidades de su industrialización, en Brasil el sindicalismo ha sido menos fuerte que en Argentina, por ejemplo, pero por eso mismo fue también más dócil al Estado y a los gobernantes en turno, aun bajo la dictadura militar de 1964 a 1985.

Todo esto sólo varió parcialmente con el retorno a la democracia. La volatilidad partidaria se reinstaló aun antes del cambio de régimen. En ese momento sirvió para desarmar el pseudosistema bipartidista diseñado por la dictadura, descomposición animada por los mismos militares que para entonces temían que a la sombra del bipartidismo forzoso se consolidara como dominante el opositor Partido del Movimiento Democrático Brasileño (PMDB). ${ }^{6}$

La transición a la democracia determinó por tanto en Brasil una reaparición del sistema inestable de partidos. Sin embargo también aquí es preciso ver las novedades, pues las perspectivas de la democracia y el papel decisivo de las elecciones (y por tanto también de los partidos) son ahora más sólidas que hace 30 o 40 años. ${ }^{7} \mathrm{Al}$ mismo tiempo, y al igual que en Argentina, la fuerza de otros actores que fueron importantes durante la dictadura o aun antes, como los militares, la Iglesia católica y los sindicatos, se ha debilitado.

Otros dos hechos a tomar en cuenta en la transición brasileña son la reforma constitucional y la situación económica. Empecemos por la segunda. Brasil tuvo un gran desempeño económico entre 1968 y principios de los años setenta, no sólo por sus grandes

${ }^{6}$ Pareciera como si la idea de generar artificialmente dos partidos hubiera sido copiad a de Getulio Vargas, que hizo algo similar (aunque con distinto objetivo) al final de su primero $y$ prolongado periodo de gobierno (1930-1945). Pero salvo en contados casos, el bipartidismo estricto no parece estar en el horizonte inmediato de los países latinoamericanos, si bien en situaciones como las de Argentina y Chile las. coaliciones políticas y parlamentarias pueden jugar papel similar.

${ }^{7}$ Sin contar que una formación importante como es el Partido de los Trabajadores (PT) parece apuntar a una vida más larga $y$ a una organización más estructurada que la que suele ser normal en otros partidos. 
tasas de crecimiento en general, sino de expansión industrial en particular. La magnitud de este crecimiento industrial ha sido comparado con el de Estados Unidos luego de la guerra civil o el de la Unión Soviéticâ en la época del primer plan quinquenal. Por sí solo este fenómeno era un indicador de cambios más globales que se estaban produciendo a consecuencia de la evolución del sistema económico internacional.

Sin embargo, más allá de los efectos propagandísticos y de la impresión lograda en el ámbito latinoamericano e internacional por el avance de la economía brasileña, es claro que ésta había entrado en un periodo de dificultades ya a mediados de los setenta, por lo que ni el tardío régimen militar ni el nuevo gobierno democrático podían basarse en las anteriores expectativas. Brasil seguía manteniendo en los años ochenta (aunque no tanto actualmente) un buen dinamismo comercial externo, pero ni sus tasas de crecimiento ni las esperanzas laborales y salariales de la población eran ya muy optimistas -para no hablar de una estructura de distribución del ingreso extremadamente injusta (sólo comparable a la de México por lo regresiva) que no fue alterada ni siquiera en el mayor periodo de prosperidad. De modo que, pese al desarrollo alcanzado por el país, la economía no fue un buen compañero de la política durante la transición.

En cuanto a la asamblea constituyente llamada a reformar la ley suprema, jugó en colectivo un papel similar al que tuvo en Argentina la figura de Alfonsín. Entre los cuatros países que estudiamos en esta investigación, en el primer gobierno de la transición a la democracia se registra una diferencia. Dos de ellos (Uruguay y México), tomando en cuenta el tipo de personal político y de partido predominante, tuvieron (o tiene todavía en el caso de México) una transición que podríamos catalogar como más marcada por consideraciones realistas y pragmáticas. En contraste, en Argentina y Brasil en algunos momentos y ámbitos predominaron las ilusiones políticas. Alfonsín, según vimos, traía ideas de castigar a los militares, deslindarse del imperialismo (y por tanto de Estados Unidos) y realizar reformas económicas progresivas. Sólo en el primer aspecto tuvo algunos logros, que situaron a Argentina por encima de la media de los países latinoamericanos que habían vivido violaciones masivas de los derechos humanos. En lo demás el idealismo lo debilitó, sin que se avanzara gran cosa en las metas postuladas, $y$ de hecho el cambio de rumbo de su sucesor no sólo debe atribuirse a maquiavelismo, sino también a las lecciones que había tomado de la frustrada experiencia alfonsinista.

En Brasil la aspiración del cambio social no encarnó en el gobierno, que dada la muerte del candidato electo Tancredo Neves, había recaído en un político conservador (José Sarney), sino en la Asamblea Constituyente. Ésta emitió un documento no sólo muy largo y prolijo sino también pleno de compromisos sociales, amén de incluir también la previsión de ser revisado dentro de cierto periodo, lo que ponía un elemento de incertidumbre adicional en torno a la posibilidad de su aplicación. En casos como este 
no surgen programas viables sino resultados coyunturales debidos a la presión política y a las promesas arrancadas a la sombra de la transición, con el idealismo o la ideologización propios de una circunstancia en que las principales fuerzas de oposición vienen de un largo periodo de exclusión del poder y de la participación en la toma de decisiones. En tal contexto puede existir también un clima de repliegue y concesiones (al menos verbales) por parte de fuerzas conservadoras -militares, clases altas locales, intereses económicos y financieros internacionales, potencias extranjeras- que dan a la izquierda y a las tendencias progresistas en general la posibilidad de desplegarse. Esta capacidad de expresión o incluso de concreción legal de objetivos no garantiza empero que haya los recursos y condiciones para una realización efectiva de lo que se busca. Se producen luego reflujos que, como se ha visto en distintos países de América Latina, concluyen en un triunfo del realismo político y económico. ${ }^{8}$

La administración de José Sarney fue por estas y otras razones también débil, pero logró la consolidación democrática y mantuvo una buena relación con los militares que se alejaron cada vez más de la escena cotidiana del gobierno, si bien nadie duda que detrás del telón siguen siendo una fuerza política de peso.

\footnotetext{
Aunque con un sesgo particular, estos dilemas son expuestos por Juan Carlos Casas, Nuevos, 1991.
}

MÉxICO

En México el primer problema a resolver es el de establecer a qué periodo o administración gubernamental nos referimos cuando hablamos del primer gobierno de transición a la democracia. Evidentemente hay diferencias en relación con los países sudamericanos, aunque ello no determina una incomparabilidad absoluta, pues sin perjuicio de su originalidad histórica y de su ritmo peculiar de evolución que marca una cronología un poco distinta y más tardía de transformación, el caso mexicano también presenta rasgos que facilitan interesantes comparaciones.

¿Cuándo comienza la transición a la democracia en México? En ninguno de los casos tratados, a decir verdad, la respuesta es fácil, pues en América Latina los regímenes autoritarios suelen establecer, desde el momento de su instalación, alguna suerte de compromiso verbal y a veces hasta un temprano cronograma de retorno a la democracia. ${ }^{9}$ Pero en México, por no haberse dado hasta ahora una alternancia del partido en el gobierno pero sí en cambio importantes transformaciones del régimen, la pregunta se vuelve más pertinente. Podemos hablar de una

9 Es claro también que estas promesas no son muchas veces sinceras o, peor aún, que lo que entienden algunos regímenes autoritarios por "democracia" puede parecer extraído del léxico de "1984", más que de las definiciones usuales del término, pero ello no evita que a veces se instalen a la sombra de estas declaraciones conatos de negociaciones que ruelven más confusa la fecha real del inicio de la transición a la democracia. 


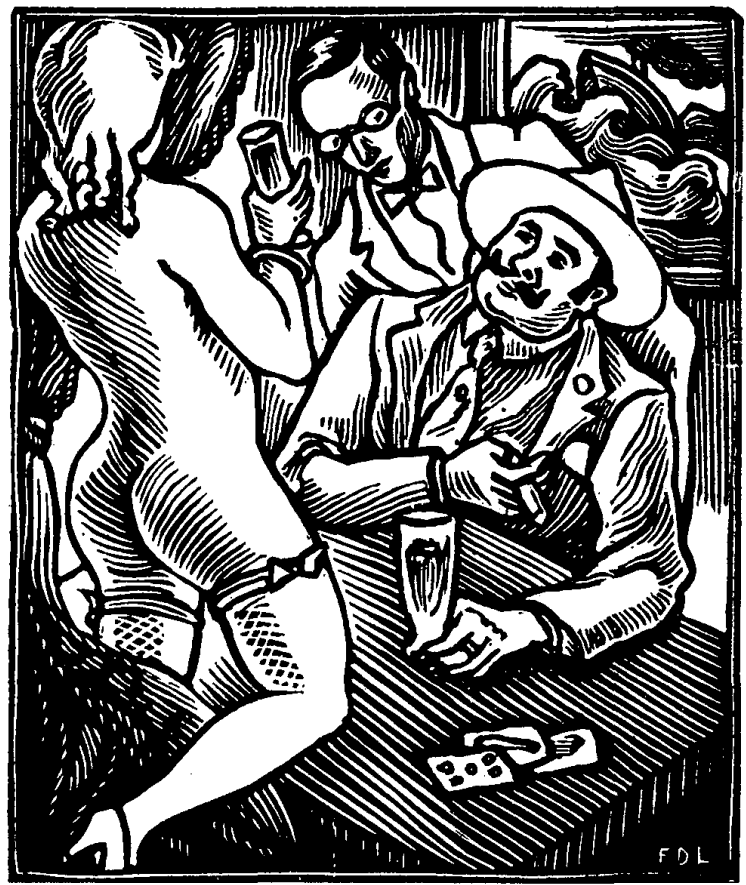

transición larga, por lo menos iniciada en la primera mitad de los ochenta con el reconocimiento de algunos triunfos electorales del Partido Acción Nacional en comicios locales. Pero este proceso, muy limitado y frenado por el propio gobierno, se profundizó entre las elecciones de 1988 y las de 1997. Estas últimas marcaron la pérdida del control del gobierno de la capital federal por parte del PRI. Además, las diversas calamidades del año terrible de 1994 obligaron al gobierno entrante (el que encabeza Ernesto Zedillo Ponce de León) no sólo a admitir elecciones li- bres sino también a apoyarse cada vez más en negociaciones con los partidos de oposición (unificados o divididos según la ocasión) para poder tomar decisiones claves en materia política o económica.

La situación presenta singularidades que sin embargo no son, como ya dijimos, obstáculo insalvable para la comparación. No cabe duda, para empezar, que más allá de sus originalidades el régimen emanado de la revolución mexicana constituyó una variante de autoritarismo (y, junto con el de Egipto, uno de los ejemplos más 
exitosos de autoritarismo, según autores como Juan Linz o Samuel Huntington).$^{10} \mathrm{Y}$ aunque el tema haya merecido cierto debate, ${ }^{11}$ parece claro que se está procesando un cambio de régimen en la medida en que se han transformado las relaciones de poder entre Estado y sociedad civil y entre los partidos y el gobierno, y la realización de elecciones cada vez más depuradas es un hecho nuevo que cambia las normas de legitimidad y de distribución entre fuerzas políticas de muchos cargos de la estructura del Estado.

La diferencia y la semejanza con los otros países radica, entre otros elementos, en el papel que juegan el gobierno y el Partido Revolucionario Institucional (PRI) en la transición. Si nos fijamos en el renglón de las semejanzas, habría cierta similaridad con el caso brasileño por el hecho de que las directivas de la transición han sido negociadas en un escenario en que el régimen autoritario, más allá de sus problemas, ha tenido una participación preponderante. La diferencia esencial consiste en que el centro del poder durante el autoritarismo fincaba aquí en una fuerza civil (una elite política y un partido cuasi único); y como las fuerzas civiles organizadas en partidos tienen legitimidad -a diferencia de las organizaciones militares, que se suponen profesionalmente dedicadas a otra 1970 .

${ }^{10}$ Ver Huntington y Moore, Autboritarian,

"Sobre todo por parte de Manuel Antonio Garretón, que habla de una extensión más que de un cambio de régimen en México, por el hecho de que no ha habido rotación del partido en el gobierno. función- para participar, dentro de ciertas normas, en la política democrática, se da la posibilidad de que el anterior partido dominante o hegemónico subsista aunque en forma cambiada y disminuida. (La misma experiencia de los países europeos recientemente reformados nos muestra que los remanentes partidarios de los antiguos regímenes totalitarios o autoritarios, una vez reformados, no sólo tienen capacidad de sobrevivir, sino incluso de reconquistar posiciones y hasta de volver al gobierno por medio de la competencia electoral.)

Para ello no sólo deben reformarse el Estado y el régimen, sino también el antiguo partido oficial. En cl caso de México, no menos que en Europa central y del este, uno de los pasos claves (todavía no consumado) de la transición es el de la ruptura de la simbiosis Estado-partido. ${ }^{12}$ Cuando esta fisión se produce no cambia sólo el Estado, sino también el partido (en caso de que sobreviva). Esto es visible actualmente en México: a pesar de que el PRI sigue en el gobierno, sus privilegios se han visto disminuidos y su capacidad de determinar a priori el resultado de las elecciones se ha reducido aún más. Gracias a ello el PRI paradójicamente tiende a ser hoy más partido que antes, en el sentido de ser sólo una parte de un todo competitivo y ya no tanto un instrumento electoral (o pseudoelectoral) de la presidencia de la repú-

\footnotetext{
${ }^{12}$ Aunque con esta comparación no se pretende que en México el papel del partido hegemónico y su relación con el Estado haya sido el mismo que en el conjunto de los llamados países socialistas.
} 
blica, como lo fue en la época de oro del sistema autoritario mexicano.

Se ha dado también una transformación completa del grupo de los partidos de oposición. Los llamados "partidos paraestatales" antes adheridos al sistema del "PRI-gobierno" como falsa oposición, han prácticamente desaparecido, y los partidos realmente opositores (sobre todo el Partido Acción Nacional o PAN y el Partido de la Revolución Democrática O PRD) han cobrado un peso equivalente en muchos aspectos al del PRI, como se ve en el pasaje de varias gubernaturas de provincia a manos de los primeros. Pero debido no sólo a la competitividad creciente de la oposición, sino también a la capacidad de supervivencia electoral del PRI, se ha dado también en varios estados el fenómeno de los "gobiernos divididos", en los que el poder ejecutivo, sea del color que sea, debe arreglárselas para desempeñarse con un Congreso donde no tiene mayoría legislativa. Esto se verifica también en la relación entre el propio poder ejecutivo federal y el Congreso de la unión, donde el conjunto de la oposición es mayoría absoluta.

Un punto central en la transición mexicana es el de la reforma del Estado o reforma estructural y su relación con el cambio de régimen y las correspondientes transformaciones de la cultura política. En un principio la reforma económica y administrativa fue empujada por la crisis de la deuda y la caída de los precios del petróleo a principios de los años ochenta. Pero lo que se presentaba inicialmente como búsqueda de un saneamiento financiero se convirtió en un cambio por acumu- lación de acciones del papel del Estado en la economía y de la gestión gubernamental en general. Esto, al incidir en las tasas de crecimiento, el nivel de empleo y la competitividad de la economía en lo interno y en lo internacional, no podía dejar de repercutir en las relaciones corporativas y clientelares mediante las cuales el sistema del PRI-gobierno extendía sus tentáculos hacia la sociedad civil.

Pero el cambio no sólo era obligado por la crisis y las exigencias de las agencias financieras internacionales que acudieron en socorro del gobierno mexicano en la década pasada. También fue bandera de una elite tecnocrática priista que soñaba poner al país a la altura de la nueva realidad mundial, aunque sin perder la aspiración de que su sistema político siguiera en manos de la misma elite. En especial el llamado "grupo compacto", de la época del gobierno de Carlos Salinas de Gortari (1988-1994), buscó una evolución controlada que llevara del autoritarismo y las elecciones fraudulentas a una combinación sui géneris de estos mismos métodos con otros más adaptados a la competencia democrática, a efectos de un aterrizaje suave que garantizara la continuidad de largo plazo, con legitimidad reforzada, del PRI en el gobierno.

La reforma estructural que luego de un periodo de penurias habría de llevar el bienestar a la mayoría de las familias era un elemento central en esta estrategia. Sin embargo, guiada por su propia lógica, la economía impuso otras condiciones a los gobiernos mexicanos de los años ochenta y noventa. En la época de mayor profundidad de la crisis (1982-1988 aproximadamen- 
te), la necesidad de decretar severas medidas con muy negativos impactos sociales, a la vez que reforzó la oposición masiva al régimen (primero capitalizada por el PAN y luego por la coalición que habría de devenir en PRD) indujo al gobierno a realizar algunas concesiones electorales que, si bien tímidas y muchas veces a la postre revertidas, marcaban una diferencia con la práctica de años anteriores. En los primeros años noventa la relativa prosperidad económica asegurada por el ingreso de capitales extranjeros sirvió para que el régimen, sin dejar de hacer algunas importantes concesiones (o "concertacesiones" como las bautizó la jerga política), sobre todo al PAN, estableciera su estrategia un tanto fantasiosa de cambio y continuidad que fue sepultada por la segunda gran crisis económica que estalló a fines de 1994, acabando con las últimas pretensiones de perduración del régimen priista.

Esta crisis no era, como la de los años ochenta, el resultado de una estructura interna económica y administrativamente obsoleta, sino un anuncio de los nuevos tiempos de volatilidad del sistema económico internacional, un fenómeno que nadie puede garantizar que no se vuelva a repetir (de hecho ya se está repitiendo en varios puntos de la red económica y financiera mundial) y que plantea otros requisitos de manejo de la legitimidad política, como la negociación de acuerdos claves sobre la política económica entre gobierno y partidos de oposición, acuerdos en que el gobierno ya no puede aparecer monologando, como ocurría hasta los años ochenta y ni siquiera tratando de imponer condiciones des- de una posición de fuerza, como en la primera mitad de los noventa, sino logrando consensos muy trabajosamente y de forma imperfecta y transitoria. Así como la economía fue pretexto para los golpes de Estado y la instauración de dictaduras en América Latina en los años sesenta y setenta, en los ochenta y noventa ha conspirado contra la fortaleza de los regímenes autoritarios. ${ }^{13}$

En cuanto a los actores corporativos, dijimos al hablar de Brasil que en los países con tradiciones partidarias débiles pero con Estados fucrtes y un desarrollo industrial considerable, la relación de apoyo fundamental del Estado ha dependido de corporaciones obreras más o menos dóciles. Esto en México se vio alterado, en los últimos quince años, en primer lugar por la propia lógica de modernización del Estado, que llevó en algún momento a la tecnocracia a despreciar a la dirigencia sindical corporativa (de lo que luego debió en parte arrepentirse, pues ésta constituía un pilar muy importante del poder y la disciplina priistas); y en segundo lugar por la transformación de los criterios de distribución de cargos estatales y botines políticos acarreada no sólo por la reforma del Estado sino también por el avance de la democracia y la competencia electoral.

En cuanto a la Iglesia católica, en México ha tenido un papel tal vez más complejo que en otros países latinoamericanos, dificil de explicar en pocas líneas. Si bien nunca simpatizante

${ }^{13}$ Lo cual, desde el punto de vista teórico, nos debe servir para dudar de las relaciones estrictas que a veces se pretenden establecer entre estructura económica y régimen político. 
del régimen posrevolucionario (sus simpatías en todo caso hubieran estado del lado del PAN), por razones prácticas la Iglesia funcionó durante décadas sintonizada con el orden priista. Actualmente, liberada de la tutela del Estado, es una fuerza prudente y conservadora, pero claramente crítica en puntos claves (sobre todo de política económica), enviando la señal de que no está dispuesta a pagar con apoyo político las transformaciones legales que le dieron plena voz y personalidad jurídica en la coyuntura mexicana presente. Aparte de cierto revanchismo eclesiástico por años de silencio obligado, la Iglesia católica, no menos amenazada en México que en otras latitudes latinoamericanas (por ejemplo Centroamérica o Chile) por el avance de las Iglesias cristianas evangélicas, no quiere hipotecar su futuro al apoyo o siquiera la connivencia con una fuerza de porvenir incierto como es el PRI en el gobierno.

Respecto a los militares, por el hecho de haber sido el mexicano un régimen autoritario pero civil, las fuerzas armadas tuvieron un peso moderado en el mismo. Curiosamente (y esto sí es una diferencia de nota con los otros países estudiados) el ascenso a primer plano de las fuerzas armadas coincide con la democratización relativa del régimen. Ello tiene que ver sobre todo con la vigorosa reaparición de varias orgänizaciones guerrilleras (no sólo en Chiapas, sino también en otros puntos de la república) pero también con otras causas, como el debilitamiento del régimen y sus puntos de apoyo tradicionales como el corporativismo sindical, y situaciones de inestabilidad que han producido una incertidumbre a la cual no estaba acostumbrado el sistema político mexicano.

Aunque en un segundo plano, los militares han cobrado fuerza en la transición, viendo justificado su protagonismo por el desafío armado de las guerrillas. Pero por otro lado, en vista de los saldos de las dictaduras sudamericanas, no es ya época de mesianismos castrenses (ni su apoyador de antaño, Estados Unidos, si bien muy atento a la situación de Chiapas, está dispuesto a endosar facilmente nuevos golpes de Estado), y por eso la acción de las fuerzas armadas se combina peculiarmente con el desarrollo de un sistema politico que, si bien inestable y ya no hegemonizado por nadie, es cada vez más plural, y donde las salidas autoritarias y las violaciones a los derechos humanos, aunque no descartadas, son cada vez más difíciles de legitimar. La acción militar en un panorama así se conjuga con el sometimiento formal a la autoridad civil (aunque el grado real de dicha subordinación no es del todo claro cuando se realizan operaciones bélicas o parabélicas en el terreno del conflicto armado) y con una invocación constante al estado de derecho, un poco a semejanza de lo que sucedía en Perú en la década pasada (antes del "autogolpe" de Alberto Fujimori) cuando las fuerzas armadas combatían a Sendero Luminoso y otras guerrillas.

\section{URUGUAY}

La crisis política de los años sesenta y setenta en Uruguay fue en gran medida resultado del impacto de una crisis 


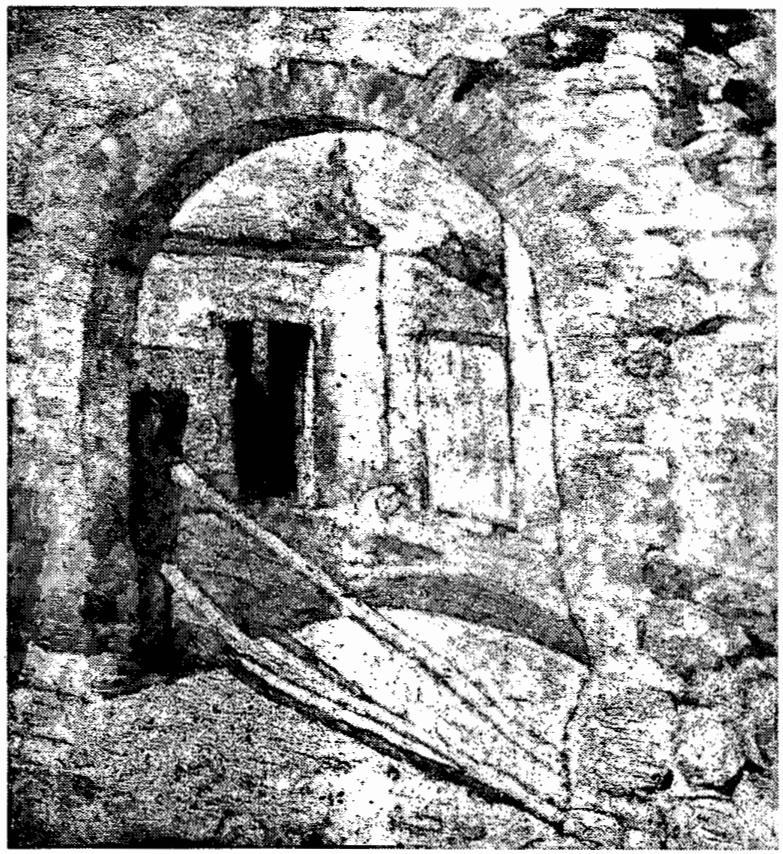

económica de gran profundidad en un sistema político estancado. En lo económico ello significó la pérdida de la inserción que el país había tenido desde el siglo XIX en el sistema internacional. En lo socioeconómico, la dificultad de seguir sosteniendo un Estado de bienestar muy desarrollado en comparación con el promedio latinoamericano. En lo político-administrativo, la coadministración del Estado por los llamados partidos tradicionales (Partido Nacional y Partido Colorado) no fue capaz de abrirse a la innovación ni a la oposición de izquierda, ni de dar respuesta a las necesidades de re- forma de la economía y del Estado. Pese a que toda la tradición política apuntaba en contra de la intervención militar profesional, el país terminó cayendo en un largo paréntesis de dictadura castrense.

Con estos antecedentes es comprensible que, al volver la democracia, por un lado el tema central fuera el de la gobernabilidad, y por otro, que la transición no pudiera ser lograda sino por medio de un acuerdo entre partidos, ${ }^{14}$ pues si dichas organizaciones son importantes en cualquier pro-

\footnotetext{
${ }^{14}$ Véase Dutrénit, Maremoto, 1994.
} 


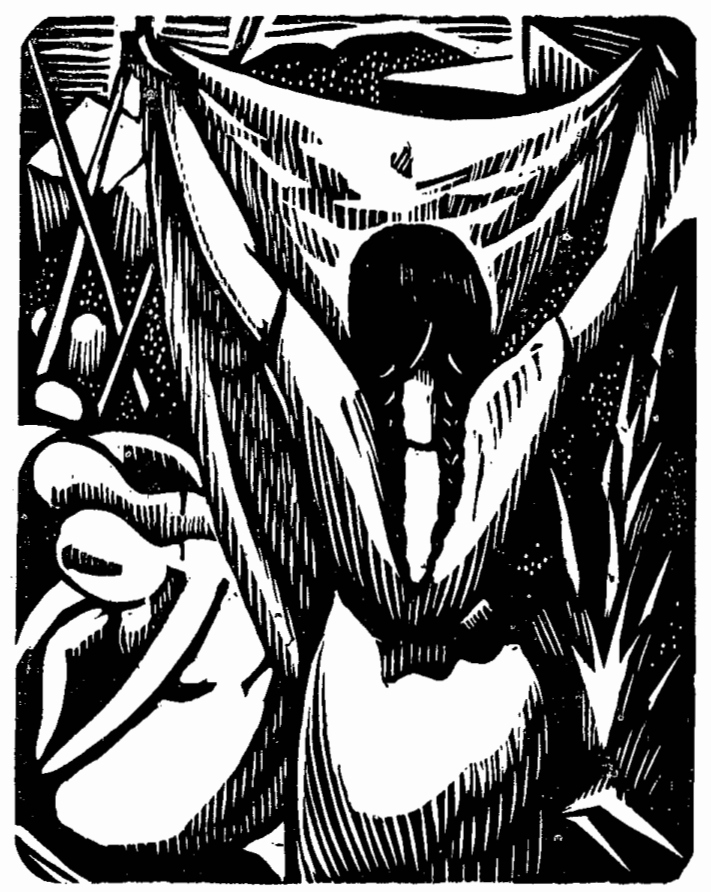

ceso de transición a la democracia, más lo son en un país en que durante más de un siglo han permanecido, con pocas interrupciones, como los principales centros de poder y toma de decisiones. Sin embargo, el proceso no se llevó de forma armónica, ni sin que los militares siguieran teniendo un importante papel como árbitros de la negociación en los tensos meses finales del régimen autoritario.

Como es sabido, el paso decisivo hacia el cambio de régimen sólo pudo ser dado por medio de un acuerdo entre la cúpula militar, uno de los parti- dos tradicionales, el Partido Colorado, y la coalición de izquierda, el Frente Amplio. El Partido Nacional, por esta vez en una posición aún más de izquicrda, se cerró a toda negociación con las fuerzas armadas. La gobernabilidad fue asegurada inicialmente por el ingreso de la izquierda a las negociaciones, lográndose la salida de los militares del gobierno. En seguida, no obstante, se hizo necesario un nuevo arreglo con otros actores, pues la izquierda no estaba dispuesta, en igual medida, a avalar decisiones económicas restrictivas ni mucho menos a amnistiar las viola- 
ciones a los derechos humanos cometidas por las fuerzas armadas durante la dictadura. El segundo paso recayó, en consecuencia, sobre todo ${ }^{15}$ en los dos partidos tradicionales.

El Partido Nacional dio un giro hacia la derecha luego de su postura radical en las postrimerías del régimen autoritario. Lo hizo no sólo en función de la consolidación del nuevo régimen y la estabilización de la economía sino también con miras a futuras elecciones, tratando de reconstituir su imagen como "fuerza tranquila", capaz de gobernar y de conciliar distintas posiciones adversarias. En un clima de reconciliación, donde el temor de una reversión autoritaria en caso de que los partidos fracasaran era aún muy fuerte, el Partido Nacional tomó así una decisión tan polémica como había sido antes la de abstenerse de conversar con las fuerzas armadas: aliado al Partido Colorado aprobó la llamada "ley de caducidad", que aseguraba la impunidad por las violaciones a los derechos humanos durante el periodo autoritario.

Como se ve, la cuestión de la gobernabilidad $^{16}$ recayó sobre los partidos, mas no de forma homogénea, como si. se tratara de una suerte de responsabilidad consensualmente compartida, sino de acuerdo con relaciones en que se alternaron situaciones de cooperación y de conflicto, según la conveniencia de cada organización matizada

\footnotetext{
${ }^{13}$ No incluimos en estos análisis la participación de otro partido, la Unión Cívica, pues pese a su importancia coyuntural en esa época, ha tenido en general un muy reducido peso político.

${ }^{16}$ Para un tratamiento general del tema de la gobernabilidad, véase Alcántara, Gobernabilidad, 1995.
}

por los respectivos principios ideológicos y programáticos. En el detalle se ven trayectorias erráticas pero en conjunto también cierta lógica tendiente a asegurar el camino de la transición. En tal sentido, dos partidos hicieron en momentos críticos acuerdos que en principio se supondría que no harían. El Frente Amplio, contra toda expectativa, aceptó participar en el llamado Pacto del Club Naval (1984) por el cual se finiquitó la dictadura. El Partido Nacional, a su vez, aceptó votar la Ley de Caducidad de la Pretensión Punitiva del Estado. El que jugó consistentemente como pivote de la gobernabilidad, exhibiendo su disponibilidad a apurar todos los tragos amargos (y afianzando con ello su papel preponderante en el cambio de régimen) fue el Partido Colorado.

Pero con este juego de tres se verificaba también -como ya lo estaban indicando las cifras electorales desde 1971- que el histórico esquema bipartidista se estaba terminando en Uruguay para ser sustituido por otro de tres partidos cada vez más igualados en sus potenciales electorales y en su peso político específico, lo cual determinaba también para los dos partidos tradicionales (Nacional y Colorado) una incertidumbre adicional, pues una de las suposiciones corrientes en el debate político era la de que el bipartidismo podía restaurarse, pero reconstituido por la polaridad entre el Frente Amplio y alguno de los partidos tradicionales, con la eliminación del otro de estos últimos. ${ }^{17}$ En tal hipótesis,

${ }^{17}$ Un poco a semejanza de to ocurrido en el sistena británico de partidos de este siglo, 
desde la perspectiva de mediados de los ochenta parecía que el candidato a la desaparición o a la "jibarización" era el Partido Nacional. Esta es probablemente una de las razones por las cuales éste hizo el cambio de posición que le llevó a aprobar la ley de caducidad en el parlamento. Fuera que tal estrategia rindiera frutos o no, el hecho es que la expectativa de una larga hegemonía colorada se diluyó al final del primer gobierno de la transición, cuando el nacionalismo triunfó en las elecciones de 1989. Desde entonces, si bien no ha quedado del todo excluida la posibilidad de que el bipartidismo se reconstituya con el sacrificio de alguna de las dos agrupaciones tradicionales, el hecho es que se ha mantenido el equilibrio tripartito entre éstas y el Frente Amplio.

Vemos así cómo la gobernabilidad, más que centrarse en grandes operativos consensuales como el intentado inicialmente con la llamada Concertación Nacional Programática (CONAPRo), se basó en una dinámica de ajustes pragmáticos entre los principales actores de la transición (sobre todo los partidos) dentro de algunos grandes límites (o si se quiere reglas del juego) que los mismos en términos generales respetaron. Sobre todo, la adhesión a las instituciones liberal-democráticas (lo que para la izquierda significó una renuncia a las aspiraciones revolucionarias) y la aceptación de ciertos criterios básicos en el manejo de la economía, tema del que más adelante hablaremos.

donde el Partido Liberal fue reemplazado por la opción de izquierda del laborismo.
En cuanto a los otros actores potenciales de la transición, sólo el sindicalismo siguió siendo un actor importante en el correr de este periodo. La Iglesia católica, aunque con cierta influencia, siempre ha sido una fuerza política disminuida en el panorama uruguayo. Y los militares, si bien conservaron coherencia institucional y aseguraron permanecer intocados por la casi totaliclad de los delitos cometidos bajo la dictadura, perdieron incidencia en la toma de decisiones.

La economía, que había sido un punto fundamental en la grieta de la democracia uruguaya, fue ahora menos problemática. Si bien con altibajos, el país logró un cambio en su inserción en la economía mundial, rompiendo el ciclo devaluatorio unido a la monoproducción y la monoexportación ganaderas. ${ }^{18} \mathrm{Y}$ pese a la protesta gremial continuada, al cambiar el papel que la izquierda tenía en el sistema político se modificó también la relación entre la economía, los sindicatos y la política. Al igual que en los otros países estudiados, los cambios económicos que acompañan o anteceden a la transición tuvieron aquí tanto que ver con las nuevas relaciones gobierno-oposición como con una comprensión (o al menos aceptación resignada) por parte de las fuerzas políticas más significativas de que algunas variables económicas se manejan por medio de lógicas suprapartidarias (de lo que es un síntoma, por ejemplo, la tendencia a la autonomización jurídica de las bancas centrales).

\footnotetext{
${ }^{18}$ Ver Varela, Uruguay, 1991.
} 


\section{CONCLUSIÓN}

En las páginas anteriores hablamos de dos tipos distintos de transición a la democracia en países latinoamericanos. Más allá de las razones específicas de cada caso particular a las que se atribuyan las causas de la crisis y de la intervención militar en países sudamericanos, es evidente que la misma finalmente se resumió en una cuestión de lucha por la definición de las relaciones de poder dentro de los límites de organizaciones de tipo Estado-nación. Por una razón u otra el poder civil no mantuvo las riendas del poder, ni por vías autoritarias ni mucho menos democráticas. El mando fue tomado por aquella institución que, al margen de toda otra especulación teórica, sabemos que encarna la lógica final de cualquier Estado, o sea las fuerzas armadas.

Éstas, por distintos motivos (discrepancias en su interior, presiones del extranjero, limitaciones implícitas en su especialización profesional), si bien en países como Brasil o Chile supieron mantener por un largo plazo el control político, no fueron capaces de dar a luz un régimen estable cortado a su medida. El retorno de la democracia, por tanto, acabaría apoyándose en partidos y elites políticas más o menos tradicionales o sea, en el regreso de la competencia política basada en ciertos límites. Ya hemos señalado algunos de estos límites, sobre todo los que tienen que ver con la inserción de cada país en el sistema económico internacional al que están cada vez más adscritos, o también las relaciones económicas y políticas con la gran potencia del área, Estados Unidos.
En el caso de México, en cambio, la transición a la democracia no siguió una secuencia de crisis y derrumbe de la democracia, dictadura militar y retorno a la democracia, sino que partió de la decadencia, el conflicto y la reforma parcial de un régimen autoritario civil muy estable y de larga duración, uno de los pocos ejemplos latinoamericanos -junto con Brasil y $\mathrm{Cu}-$ ba posrevolucionaria- en que no podemos dudar de la existencia de un Estado consolidado. La transición tuvo aquí algunas variables similares a las de los países ya citados, pero también otras muy propias, apuntando al desgaste de un esquema autoritario corporativo de distribución de prebendas entre elites públicas y privadas y de mantenimiento de clientelas populares muy amplias. El cambio fue también auspiciado por la crisis económica y la presión estadunidense. La suma de los factores empujó al régimen a la democratización y no a la profundización del autoritarismo.

El trasfondo de la salida de los regímenes autoritarios no fue sólo cuestión de la reconstrucción de un sistema de autoridad sobre nuevas bases de legalidad y legitimidad. Ciertamente muchas veces se ha visto en estos términos a gran parte de los problemas latinoamericanos. Pero la problemática fue (o es) también administrativa y de gestión: debía buscarse una nueva inserción en la economía internacional y un nuevo modelo de administración pública, toda vez que las economías nacionales reestructuradas luego de 1929 se deshicieron como resultado de los cambios sobrevenidos en la segunda posguerra. Si la materia econó- 
mica no era sólo económica, la cuestión política no se reducía sólo a un asunto de poder. Por tanto, la recuperación democrática debe verse como parte de un conjunto más amplio que integra los mencionados elementos de autoridad estatal, pluralismo político (que implica interacción entre gobierno y oposición y por tanto un sistema de distribución de poder entre partidos en el marco de una competencia electoral), reestructuración económica y reforma del Estado. Esto último implica nuevos criterios de gestión, de tamaño del Estado, de intervención y regulación de la esfera económica por parte del poder público y de trato del mismo con la sociedad civil.

En cuanto a las cuestiones de ingeniería constitucional como el dilema entre parlamentarismo y presidencialismo, si bien muy ligado teóricamente al problema de la gobernabilidad y la estabilidad democrática, parece hasta ahora haber sido más que nada un debate académico. El supuesto de que el sistema presidencial de gobierno, con la relativa excepción de Estados Unidos, ofrece menos condiciones de estabilidad que el régimen parlamentario, aunque no carente de argumentos, aún no ha sido convincentemente probado en América Latina, y parece difícil probarlo sin una serie de reformas constitucionales que llevarán a su adopción por un plazo medianamente largo en distintos países a la vez.

E-nail: vapg7469@cueyati.uam.nx

\section{BIBLIOGRAFÍA}

-Alcántara Sáez, Manuel, Gobernabilidad, crisis y cambio, Fondo de Cultura liconómica, México, 1995.

-Casas, Juan Carlos, Nuevos políticos y nuevas políticas en América Latina, Atlántida, Buenos Aires, 1991.

-Dutrénit Bielous, Silvia, El maremoto militar y el archipiélago partidario. Testimonios para la bistoria reciente de los partidos políticos uruguayos, Instituto Mora/Ediciones de Ciencias Sociales, Montevideo, 1994.

-Huntington, Samuel y Clement H. Moore (comps.), Authoritarian politics in modern society. The dynamics of established one-party systems, Basic Books, Nueva York y Londres, 1970.

-Linz, Juan J. y Arturo Valenzuela (comps.), The failure of presidencial democracy, Johns Hopkins, Baltimore y Londres, 1994, vol. 2.

-Rouquié, Alain, Pouvoir militaire et societé politique en Republique Argentine, Fondation Nationale de Sciences Politiques, París, 1978.

-Touraine, Alain, Actores sociales y sistemas políticos en América Latina, PREALC, Santiago de Chile, 1987.

-Varela Petito, Gonzalo, "Uruguay, en la segunda etapa de la transición a la democracia" en Carlos Barba Solano, José Luis Barros H. y Javier Hurtado (comps.), Transiciones a la democracia en Europa y América Latina, FLACsO/Miguel Ángel Porrúa/UDG, México, 1991. 


\section{SECUENCIG}

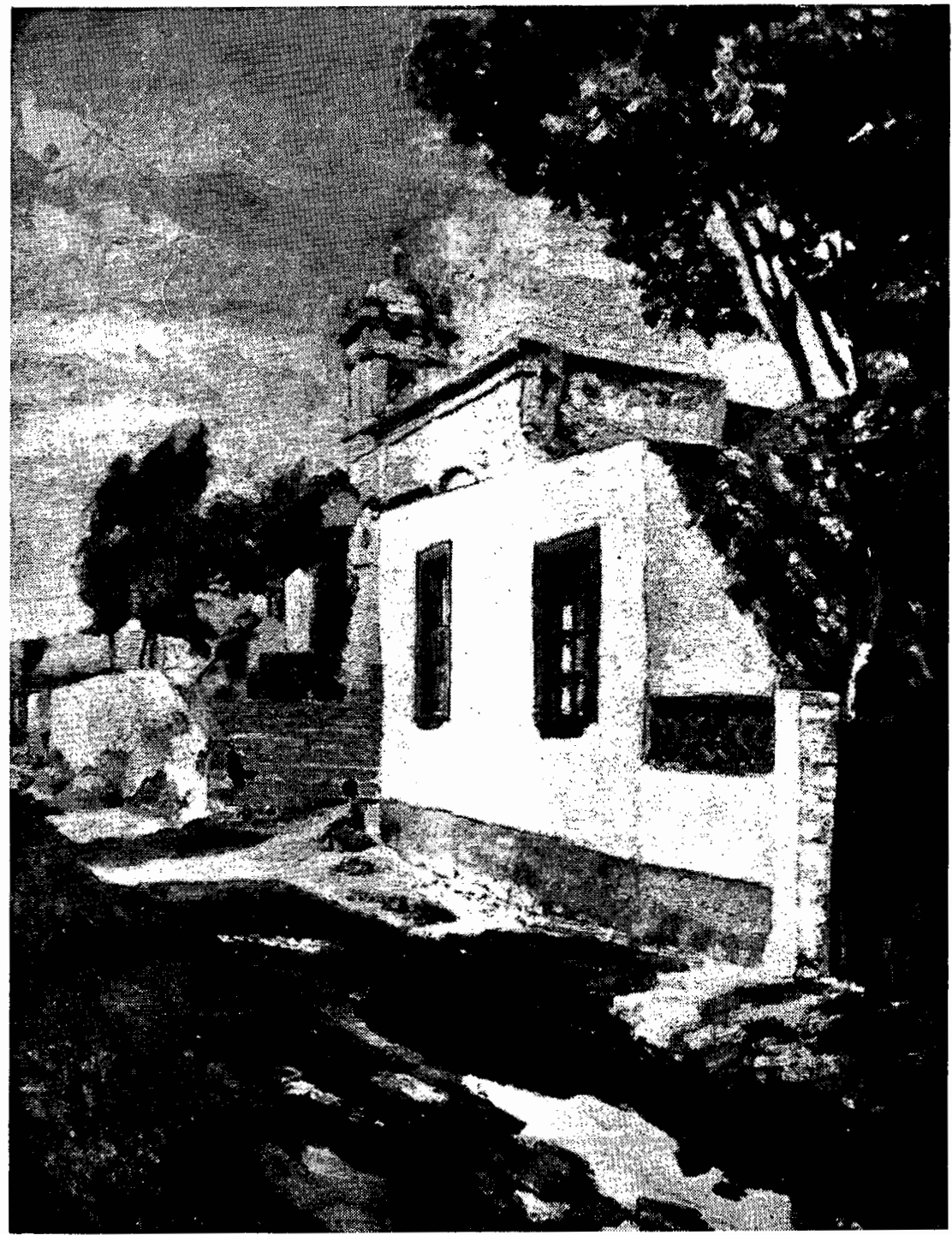

